\title{
Estrogen and Progesterone in Normal Mammary Gland Development and in Cancer
}

\author{
John Stingl
}

Received: 22 October 2010 / Accepted: 28 November 2010 /Published online: 16 December 2010

(C) Springer Science+Business Media, LLC 2010

\begin{abstract}
There is emerging evidence that the mammary epithelium in both mice and humans is arranged as a hierarchy that spans from stem cells to differentiated hormone-sensing, milk-producing and myoepithelial cells. It is well established that estrogen is an important mediator of mammary gland morphogenesis and exposure to this hormone is associated with increased breast cancer risk. Yet surprisingly, the primitive cells of the mammary epithelium do not express the estrogen receptor- $\alpha(E R \alpha)$ or the progesterone receptor. This article will review the mammary epithelial cell hierarchy, possible cells of origin of different types of breast tumors, and the potential mechanisms on how estrogen and progesterone may influence the different subcomponents in normal development and in cancer. Also presented are some hypothetical scenarios on how this underlying biology may be reflected in the behavior of $\mathrm{ER} \alpha^{+}$and $\mathrm{ER} \alpha^{-}$breast tumors.
\end{abstract}

Keywords Estrogen · Progesterone - Stem cells .

Breast tumors · Cancer

\section{Introduction}

The steroid hormone estrogen is an important mediator of the development of the mammary epithelium during puberty $[1,2]$. Considering the role estrogen has in

J. Stingl $(\bowtie)$

Cancer Research UK Cambridge Research Institute,

Li Ka Shing Centre, Robinson Way,

Cambridge, UK CB2 ORE

e-mail: john.stingl@cancer.org.uk promoting mammary gland development, it is not surprising that there is a strong positive correlation between lifetime exposure to estrogen and breast cancer risk [3, 4]. Breast tumors are typically categorized as expressing estrogen receptor- $\alpha\left(E R \alpha^{+}\right)$or as lacking expression of this receptor $\left(\mathrm{ER} \alpha^{-}\right)$. There are several paradoxical observations regarding the expression of $\mathrm{ER} \alpha$ in normal and cancer biology. The first is that the mammary epithelial cells that express ER $\alpha$ in the normal adult mammary gland are typically not proliferating [5-8]. This is counter-intuitive considering the key role estrogen has in promoting the development of the mammary ductal epithelium during puberty; this is particularly so since $\mathrm{ER} \alpha^{+}$cells are often observed to be proliferating in tumors [6]. The second paradoxical observation is that premenopausal exposure to estrogen appears to have a greater impact on $\mathrm{ER} \alpha^{-}$than on $\mathrm{ER} \alpha^{+}$tumors since the rate of occurrence of ER $\alpha^{-}$tumors decreases after menopause whereas the rate of occurrence of $\mathrm{ER} \alpha^{+}$tumors steadily increases after menopause, albeit at a slightly lower rate than before menopause [9]. This review will present a brief summary of how steroid hormones influence the different components of the mammary epithelial cell hierarchy during mammary gland development, and how this knowledge can be used to understand the origins of different types of breast tumors and the mechanisms that regulate their behavior.

\section{The Mammary Epithelial Cell Hierarchy and the Distribution of Steroid Hormone Receptors}

The mammary epithelium is composed of a series of branched ducts that, during lactation, drain milkproducing alveoli. In the virgin state, the ducts in mice 
are blind-ended structures and are embedded within mammary adipose tissue (the mouse mammary fat pad) whereas in humans, the ducts terminate in terminal ductal lobular units and the entire epithelium is embedded within a collagenous stroma. There are two main lineages of epithelial cells within the mammary epithelium: the luminal cells that line the central lumen and the underlying myoepithelial cells that are adjacent to the basement membrane. During pregnancy, there is the development of a large number of specialized luminal cells that will arrange themselves as alveoli and will secrete milk proteins and lipids during lactation. Our knowledge of the components of the mammary epithelial cell hierarchy has expanded in recent years as a result of the development of strategies to prospectively isolate phenotypically distinct subsets of mammary cells using fluorescence-activated cell sorting and assessing the properties of these cells using in vitro and in vivo functional assays [10-15]. For example, in the mouse, it has been demonstrated that most mammary repopulating units (MRUs; the operational term for cells that can generate multi-lineage ductal-lobular outgrowths when transplanted into cleared mammary fat pads) appear to reside in the basal cell compartment since they express basal specific keratins 5 and 14, but do not express the luminal-specific keratins 8 or 18 [12, 15]. Interestingly, these cells do not express ER $\alpha$ or progesterone receptor (PR) [16]. It has been recently reported that a minor subpopulation of MRUs exists within the luminal cell compartment of the mouse mammary gland, and that these cells can only be detected when co-transplanted with Matrigel $^{\mathrm{TM}}$ into cleared mammary fat pads [17]. It is not clear as of yet if these MRUs are comparable to those in the basal cell compartment or if they are more (or less?) restricted in their stem cell potential. These MRUs may also represent more mature progenitor cells that have dedifferentiated to acquire stem cell properties. The presence of stem cells in both the luminal and basal layers has also been described in the mouse prostatic epithelium $[18,19]$. MRUs in the human mammary gland have been detected in the basal cell compartment and do not express ER $\alpha$ and PR [20-22].

In vitro colony-forming assays have been used to interrogate the properties of progenitor cells in the mammary glands of both species. In the mouse, most of the progenitor cells reside within the luminal cell compartment $[12,15,16]$. These cells do not express ER $\alpha$ or the luminal cell differentiation marker Gata-3; however, they do express luminal-specific and basal-specific keratins at low levels [12]. These cells also express the alveolar cellassociated transcription factor Elf5 and surprisingly, transcripts associated with milk proteins, even in the virgin state $[12,23]$. This phenotype with low expression of both luminal and basal keratins suggests that these cells are a relatively undifferentiated progenitor cell that is an intermediate between basal stem cells and differentiated luminal cells, and the expression of milk transcripts and Elf5 suggests that these cells may represent a pool of progenitors in the virgin mammary gland that will generate alveoli during pregnancy. In vivo lineage tracing to determine the differentiation capacities of these cells has yet to be performed to confirm this hypothesis.

Most of the cells in the luminal cell compartment of the mammary glands of virgin mice appear to be relatively differentiated $\mathrm{ER} \alpha^{+}$cells. However, there appears to be a small but poorly characterized population of $\mathrm{ER} \alpha^{+}$progenitor cells $[24,25]$. The luminal cell compartment in the human breast also contains a large population of differentiated $\mathrm{ER} \alpha^{+}$cells, a population of $\mathrm{ER} \alpha^{-}$progenitors, which have a phenotype intermediate between luminal and basal cells and a population of $\mathrm{ER} \alpha^{+}$progenitors [14, 20-22, 26]. Figure 1 shows a hypothetical mammary epithelial cell hierarchy.

\section{The Role of Steroid Hormones in Regulating Normal Mammary Stem and Progenitor Cell Function}

Evidence is emerging that estrogen and progesterone exert their effects in the mammary gland primarily via paracrine interactions. For example, estrogen, which is the primary driver of ductal elongation during mammary gland development during puberty, induces secretion of amphiregulin from ER $\alpha$-expressing cells [27]. Amphiregulin in turn stimulates epidermal growth factor receptor-expressing stromal cells to secrete a factor that then stimulates mammary stem cells and other cells involved in ductal growth $[28,29]$. The paracrine factor secreted by the stromal cells has yet to be identified, although a number of candidates such as keratinocyte growth factor have been proposed [30]. In the adult, estrogen seems to have more of a permissive role since it upregulates PR, possibly via the stroma [31]. However, estrogen appears to have a key role in maintaining differentiated $\mathrm{ER} \alpha^{+}$and stem cell populations in the adult mammary gland since removal of circulating estrogens, either via ovariectomy or by a transient treatment with the aromatase inhibitor Letrozole, results in a large decrease in the number of differentiated $\mathrm{ER} \alpha^{+}$cells and a several-fold decrease in the absolute number of mouse MRUs and the engraftment potential of these MRUs 5-8 weeks after treatment [32, 33]. The effects of reduced exposure to estrogen on MRUs are thought to be mediated by inducing these cells into a quiescent state [32].

Similarly, progesterone also exerts its proliferativeinducing effects primarily via a paracrine mechanism, 
Fig. 1 Hypothetical mammary epithelial cell hierarchy with the phenotypes of the different known cellular components in both human $(H)$ and in mouse $(M)$ mammary glands. It is hypothesized that estrogen and progesterone may directly stimulate $\mathrm{ER} \alpha^{+} / \mathrm{PR}^{+}$progenitor cells to proliferate. Estrogen may also induce differentiated $\mathrm{ER} \alpha^{+} / \mathrm{PR}^{+}$cells to secrete amphiregulin, which then induces stromal cells to secrete factor (s) that stimulate stem cells to proliferate. Progesterone induces differentiated $\mathrm{ER} \alpha^{+} / \mathrm{PR}^{+}$cells to secrete RANKL, which stimulates stem cells and putative alveolar progenitors to proliferate

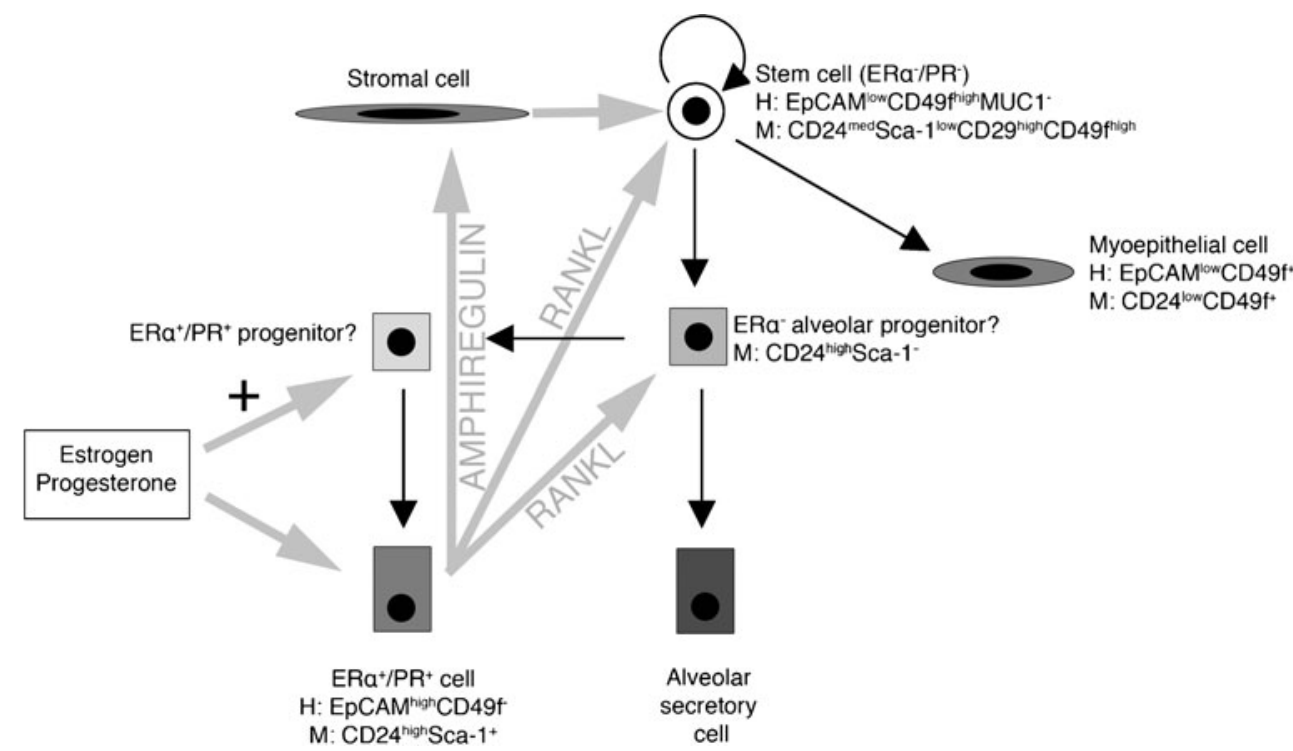

although it does require the presence of estrogen for maximal effect, presumably through upregulation of PR [32-34]. In the mouse, it has been demonstrated that progesterone induces receptor activator for nuclear factor $\mathrm{KB}$ ligand (RANKL) secretion from $\mathrm{ER} \alpha^{+} / \mathrm{PR}^{+}$mammary cells, and that this factor then directly binds to its receptor RANK and induces side-branching and alveolar development during ductal development and pregnancy [35-37]. RANKL has been demonstrated to regulate MRU function since basal cells express high levels of RANK and treatment of mice with RANKL inhibitor results in decreased clonogenic output from basal cells $[32,33]$. However, this is at odds with the observation that PR-B knockout virgin mice have normal ductal development, which is presumably dependent on the proliferation of stem cells [37]. Progesterone has also been demonstrated to mediate secretion of Wnt4 from $\mathrm{PR}^{+}$mammary cells, which can function as a paracrine factor to regulate branching morphogenesis during early pregnancy [38].

However, progesterone does not solely exert its proliferative effects via indirect mechanisms that target $\mathrm{PR}^{-}$cells since a recent publication has demonstrated that progesterone can induce transient proliferation of $\mathrm{PR}^{+}$cells in a cyclin D1dependent fashion in addition to inducing $\mathrm{PR}^{-}$cells to proliferate through a RANKL-dependent mechanism [39]. These results suggest the presence of an $\mathrm{ER} \alpha^{+} / \mathrm{PR}^{+}$ progenitor cell that is directly responsive to progesterone. This concept of a distinct $\mathrm{ER} \alpha^{+} / \mathrm{PR}^{+}$progenitor population has also been suggested by previous studies [24-26]. A summary of the direct and indirect effects of estrogen and progesterone on the different mammary epithelial cell subtypes is shown in Fig. 1.

\section{The Cell of Origin of Human Breast Tumors}

Human breast tumors are very heterogeneous with approximately five molecular subtypes recognized [40, 41]. It is not known if all breast tumors originate in stem cells and that the genetic mutations acquired during tumor progression drive the cells down different differentiation pathways, or if the heterogeneity reflects the different cellular origin of the tumors, or if it is a combination of the two mechanisms. However, it is important to keep in mind is that the gene signature of a tumor represents the average of all the cells sampled within the tumor. It is conceivable that the cancer stem cell component of the tumor is a small proportion of the total tumor cell population, and thus, its gene signature may be diluted by the bulk of the non-stem tumor cells. Evidence is emerging that metaplastic/claudinlow tumors, which are a subtype of basal breast cancer, may have a stem cell origin due to their mesenchymal and squamous metaplastic elements, their very aggressive nature, and their gene expression patterns resembling those obtained from $\mathrm{CD} 44^{+} \mathrm{CD} 24^{-/ \text {low }}$ breast cancer stem cells [42]. However, metaplastic breast cancer is a relatively rare type of tumor [42, 43], and it appears that most basal-like breast tumors have a gene expression profile that resembles those obtained from luminal progenitor cells, thus, suggesting that basal-like breast tumors may have their origin in this cell type [21]. If so, this would resolve the confusion regarding basal-like breast tumors being categorized as "basal" when they also express luminal-specific keratins [44]. Gene expression profiling of normal differentiated $\mathrm{ER} \alpha^{+}$luminal cells reveals that these cells have a gene signature that is similar to those obtained from Luminal A and Luminal B tumors [21]. The cell of origin of ErbB2- 
amplified tumors is not known, although MMTV-Neu mouse models suggest ER $\alpha^{-}$luminal progenitors could be the target in this type of cancer $[45,46]$.

\section{Influence of Steroid Hormones and Tamoxifen on Human Breast Tumor Cells}

As stated previously, estrogen appears to have a greater impact on $\mathrm{ER} \alpha^{-}$than on $\mathrm{ER} \alpha^{+}$tumors since the rate of occurrence of $E R \alpha^{-}$tumors decreases after menopause whereas the rate of occurrence of $\mathrm{ER} \alpha^{+}$tumors steadily increases after menopause [9]. Considering the emerging evidence that estrogen and progesterone have strong indirect proliferationinducing effects on mammary stem cells and putative alveolar progenitors, populations which are both $\mathrm{ER} \alpha^{-}$, it is not surprising then that the rate of incidence of $E R \alpha^{-}$ tumors decreases at menopause should these tumors be derived from these subpopulations. One can hypothesize that $\mathrm{ER} \alpha^{+}$tumors that originate in $\mathrm{ER} \alpha^{+}$luminal progenitor cells become tumorigenic via mechanisms independent of estrogen-related signaling; in such cases, estrogen may be permissive for tumorigenesis, but is not the key driver of the malignancy. As a result, tumors of this type could occur even in the low estrogen environment after menopause.

A large proportion of women with $\mathrm{ER} \alpha^{+}$tumors will become resistant to tamoxifen treatment, typically within 15 months of treatment $[5,47]$. There are several possible mechanisms for the emergence of tamoxifen resistance in $\mathrm{ER} \alpha^{+}$tumors aside from host-associated factors (e.g., drug pharmacokinetics). The first is that there is the presence of a tamoxifen-resistant clone within the starting tumor cell population that, by its inherent nature, makes it insensitive to tamoxifen treatment [48]. Experiments using $\mathrm{ER} \alpha^{+}$ breast cancer cell lines support this concept since they have demonstrated the presence of an ER $\alpha^{-}$subpopulation within $\mathrm{ER} \alpha^{+}$cell lines, and that these populations are tamoxifen- and chemotherapeutic-insensitive $[49,50]$. The second potential mechanism is that $\mathrm{ER}^{+}$cancer (stem) cells could undergo a phenotypic shift from an $\mathrm{ER} \alpha^{+}$state to an $\mathrm{ER} \alpha^{-}$state. Phenotypic plasticity has been described in human breast and melanoma cancer cell lines [51-53], in mouse hematopoietic cell lines [54], and in human melanoma tumors serial-passaged in immune-deficient mice [51]. It remains to be established if a similar phenomenon is occurring in primary human breast tumors in vivo; if so, then it raises the worrying question if cancer stem cells can be effectively targeted [55]. Another mechanism which could account for the emergence of resistance to tamoxifen is a change in $\mathrm{ER} \alpha^{+}$cancer stem cells such that they still remain $\mathrm{ER} \alpha^{+}$, but they have acquired intrinsic mutations of such that they have ligandindependent activation of ER $\alpha$-related signaling and are resistant to this drug or an agonistic response to tamoxifen (reviewed in [47, 56]). This mechanism has been the predominant model under consideration over the years, although in hindsight, it may be difficult to distinguish this mechanism from the other two if the studies are not performed at a clonal level. However, not all ER $\alpha^{+}$tumors become resistant to tamoxifen, and one could hypothesize that tumors that remain sensitive to tamoxifen originate in and are driven by $\mathrm{ER} \alpha^{+}$luminal progenitor cells [57]. It is known that approximately two thirds of $\mathrm{ER} \alpha^{+}$tumors contain a high proportion of proliferating $\mathrm{ER} \alpha^{+}$cells [6] and that estrogen has direct mitogenic effects on $\mathrm{ER} \alpha^{+}$ breast cancer cell lines $[58,59]$. Just as progesterone has a direct mitogenic effect on normal $\mathrm{ER} \alpha^{+} / \mathrm{PR}^{+}$progenitor cells [39], one can hypothesize that estrogen as well can have a direct mitogenic effect on this cell population, and that this population is expanded in cancer.

\section{Conclusion}

The information presented above summarizes how estrogen and progesterone appear to influence mammary epithelial stem and progenitor cells via indirect and possibly direct mechanisms, respectively, and how this underlying biology may explain the differences in a woman's risk of being diagnosed with either an $\mathrm{ER} \alpha^{-}$or $\mathrm{ER} \alpha^{+}$breast tumor at different stages of her lifetime. The largest unknowns in this model are the properties of the $\mathrm{ER} \alpha^{+} / \mathrm{PR}^{+}$progenitor cell in the normal mammary epithelium that may be a target for malignant transformation. It is essential that new markers that may be of use to prospectively isolate these cells from normal mammary tissue be identified. This information can then be used to further characterize cancer stem cells in $\mathrm{ER} \alpha^{-}$and $\mathrm{ER} \alpha^{+}$breast tumors.

Acknowledgements The author would like to thank Alasdair Russell, Helena Earl, Jason Carroll, Nikola Novcic, and Wilbert Zwart for scientific discussion and critical reading of the manuscript. The author would also like to acknowledge the support of Cancer Research UK, the University of Cambridge, the Breast Cancer Campaign, and Hutchinson Whampoa Limited.

Disclosure The author is a consultant of StemCell Technologies Inc.

\section{References}

1. Mueller SO, Clark JA, Myers PH, Korach KS (2002) Mammary gland development in adult mice requires epithelial and stromal estrogen receptor alpha. Endocrinology 143:23572365

2. Daniel CW, Silberstein GB, Strickland P (1987) Direct action of 17 beta-estradiol on mouse mammary ducts analyzed by sustained release implants and steroid autoradiography. Cancer Res 47:6052-6057 
3. Pike MC, Spicer DV, Dahmoush L, Press MF (1993) Estrogens, progestogens, normal breast cell proliferation, and breast cancer risk. Epidemiol Rev 15:17-35

4. Clemons M, Goss P (2001) Estrogen and the risk of breast cancer. N Engl J Med 344:276-285

5. Clarke R, Leonessa F, Welch JN, Skaar TC (2001) Cellular and molecular pharmacology of antiestrogen action and resistance. Pharmacol Rev 53:25-71

6. Clarke RB, Howell A, Potten CS, Anderson E (1997) Dissociation between steroid receptor expression and cell proliferation in the human breast. Cancer Res 57:4987-4991

7. Russo J, Ao X, Grill C, Russo IH (1999) Pattern of distribution of cells positive for estrogen receptor alpha and progesterone receptor in relation to proliferating cells in the mammary gland. Breast Cancer Res Treat 53:217-227

8. Seagroves TN, Lydon JP, Hovey RC, Vonderhaar BK, Rosen JM (2000) C/EBPbeta (CCAAT/enhancer binding protein) controls cell fate determination during mammary gland development. Mol Endocrinol 14:359-368

9. Anderson WF, Matsuno R (2006) Breast cancer heterogeneity: a mixture of at least two main types? J Natl Cancer Inst 98:948-951

10. Asselin-Labat ML, Sutherland KD, Barker H et al (2007) Gata-3 is an essential regulator of mammary-gland morphogenesis and luminal-cell differentiation. Nat Cell Biol 9:201-209

11. Shackleton M, Vaillant F, Simpson KJ et al (2006) Generation of a functional mammary gland from a single stem cell. Nature 439:84-88

12. Sleeman KE, Kendrick H, Robertson D, Isacke CM, Ashworth A, Smalley MJ (2007) Dissociation of estrogen receptor expression and in vivo stem cell activity in the mammary gland. J Cell Biol 176:19-26

13. Smalley MJ, Titley J, Paterson H, Perusinghe N, Clarke C, O'Hare MJ (1999) Differentiation of separated mouse mammary luminal epithelial and myoepithelial cells cultured on EHS matrix analyzed by indirect immunofluorescence of cytoskeletal antigens. J Histochem Cytochem 47:1513-1524

14. Stingl J, Eaves CJ, Zandieh I, Emerman JT (2001) Characterization of bipotent mammary epithelial progenitor cells in normal adult human breast tissue. Breast Cancer Res Treat 67:93-109

15. Stingl J, Eirew P, Ricketson I et al (2006) Purification and unique properties of mammary epithelial stem cells. Nature 439:993-997

16. Asselin-Labat ML, Shackleton M, Stingl J et al (2006) Steroid hormone receptor status of mouse mammary stem cells. J Natl Cancer Inst 98:1011-1014

17. Jeselsohn R, Brown NE, Arendt L et al (2010) Cyclin D1 kinase activity is required for the self-renewal of mammary stem and progenitor cells that are targets of MMTV-ErbB2 tumorigenesis. Cancer Cell 17:65-76

18. Leong KG, Wang BE, Johnson L, Gao WQ (2008) Generation of a prostate from a single adult stem cell. Nature 456:804-808

19. Wang X, Kruithof-de Julio M, Economides KD et al (2009) A luminal epithelial stem cell that is a cell of origin for prostate cancer. Nature 461:495-500

20. Eirew P, Stingl J, Raouf A et al (2008) A method for quantifying normal human mammary epithelial stem cells with in vivo regenerative ability. Nat Med 14:1384-1389

21. Lim E, Vaillant F, Wu D et al (2009) Aberrant luminal progenitors as the candidate target population for basal tumor development in BRCA1 mutation carriers. Nat Med 15:907-913

22. Raouf A, Zhao Y, To K et al (2008) Transcriptome analysis of the normal human mammary cell commitment and differentiation process. Cell Stem Cell 3:109-118

23. Oakes SR, Naylor MJ, Asselin-Labat ML et al (2008) The Ets transcription factor Elf5 specifies mammary alveolar cell fate. Genes Dev 22:581-586
24. Booth BW, Smith GH (2006) Estrogen receptor-alpha and progesterone receptor are expressed in label-retaining mammary epithelial cells that divide asymmetrically and retain their template DNA strands. Breast Cancer Res 8:R49

25. Li W, Ferguson BJ, Khaled WT et al (2009) PML depletion disrupts normal mammary gland development and skews the composition of the mammary luminal cell progenitor pool. Proc Natl Acad Sci USA 106:4725-4730

26. Clarke RB, Spence K, Anderson E, Howell A, Okano H, Potten CS (2005) A putative human breast stem cell population is enriched for steroid receptor-positive cells. Dev Biol 277:443-456

27. Wilson CL, Sims AH, Howell A, Miller CJ, Clarke RB (2006) Effects of oestrogen on gene expression in epithelium and stroma of normal human breast tissue. Endocr-Relat Cancer 13:617-628

28. Mallepell S, Krust A, Chambon P, Brisken C (2006) Paracrine signaling through the epithelial estrogen receptor alpha is required for proliferation and morphogenesis in the mammary gland. Proc Natl Acad Sci USA 103:2196-2201

29. Booth BW, Boulanger CA, Anderson LH, Jimenez-Rojo L, Brisken C, Smith GH (2010) Amphiregulin mediates selfrenewal in an immortal mammary epithelial cell line with stem cell characteristics. Exp Cell Res 316:422-432

30. Imagawa W, Pedchenko VK, Helber J, Zhang H (2002) Hormone/ growth factor interactions mediating epithelial/stromal communication in mammary gland development and carcinogenesis. $\mathrm{J}$ Steroid Biochem Mol Biol 80:213-230

31. Haslam SZ, Shyamala G (1979) Effect of oestradiol on progesterone receptors in normal mammary glands and its relationship with lactation. Biochem J 182:127-131

32. Asselin-Labat ML, Vaillant F, Sheridan JM et al (2010) Control of mammary stem cell function by steroid hormone signalling. Nature 465:798-802

33. Joshi PA, Jackson HW, Beristain AG et al (2010) Progesterone induces adult mammary stem cell expansion. Nature 465:803-807

34. Haslam SZ, Drolet A, Smith K, Tan M, Aupperlee M (2008) Progestin-regulated luminal cell and myoepithelial cell-specific responses in mammary organoid culture. Endocrinology 149:2098-2107

35. Cao Y, Bonizzi G, Seagroves TN et al (2001) IKKalpha provides an essential link between rank signaling and cyclin D1 expression during mammary gland development. Cell 107:763-775

36. Mukherjee A, Soyal SM, Li J et al (2010) Targeting RANKL to a specific subset of murine mammary epithelial cells induces ordered branching morphogenesis and alveologenesis in the absence of progesterone receptor expression. FASEB J 24 (11):4408-4419

37. Mulac-Jericevic B, Lydon JP, DeMayo FJ, Conneely OM (2003) Defective mammary gland morphogenesis in mice lacking the progesterone receptor B isoform. Proc Natl Acad Sci USA 100:9744-9749

38. Brisken C, Heineman A, Chavarria $T$ et al (2000) Essential function of Wnt-4 in mammary gland development downstream of progesterone signaling. Genes Dev 14:650-654

39. Beleut M, Rajaram RD, Caikovski M et al (2010) Two distinct mechanisms underlie progesterone-induced proliferation in the mammary gland. Proc Natl Acad Sci USA 107:2989-2994

40. Perou CM, Sorlie T, Eisen MB et al (2000) Molecular portraits of human breast tumours. Nature 406:747-752

41. Sorlie T, Perou CM, Tibshirani R et al (2001) Gene expression patterns of breast carcinomas distinguish tumor subclasses with clinical implications. Proc Natl Acad Sci USA 98:1086910874

42. Hennessy BT, Gonzalez-Angulo AM, Stemke-Hale K et al (2009) Characterization of a naturally occurring breast cancer subset enriched in epithelial-to-mesenchymal transition and stem cell characteristics. Cancer Res 69:4116-4124 
43. Reis-Filho JS, Milanezi F, Steele D et al (2006) Metaplastic breast carcinomas are basal-like tumours. Histopathology 49:10-21

44. Gusterson B (2009) Do 'basal-like' breast cancers really exist? Nat Rev Cancer 9:128-134

45. Liu JC, Deng T, Lehal RS, Kim J, Zacksenhaus E (2007) Identification of tumorsphere- and tumor-initiating cells in HER2/Neu-induced mammary tumors. Cancer Res 67:86718681

46. Vaillant F, Asselin-Labat ML, Shackleton M, Forrest NC, Lindeman GJ, Visvader JE (2008) The mammary progenitor marker CD61/Beta3 integrin identifies cancer stem cells in mouse models of mammary tumorigenesis. Cancer Res 68:7711-7717

47. Ali S, Coombes RC (2002) Endocrine-responsive breast cancer and strategies for combating resistance. Nat Rev Cancer 2:101112

48. Coser KR, Wittner BS, Rosenthal NF et al (2009) Antiestrogenresistant subclones of MCF-7 human breast cancer cells are derived from a common monoclonal drug-resistant progenitor. Proc Natl Acad Sci USA 106:14536-14541

49. Horwitz KB, Dye WW, Harrell JC, Kabos P, Sartorius CA (2008) Rare steroid receptor-negative basal-like tumorigenic cells in luminal subtype human breast cancer xenografts. Proc Natl Acad Sci USA 105:5774-5779

50. Kabos P, Haughian JM, Wang X, et al (2010) Cytokeratin 5 positive cells represent a steroid receptor negative and therapy resistant subpopulation in luminal breast cancers. Breast Cancer Res Treat (in press). doi:10.1007/s10549-010-1078-6
51. Boiko AD, Razorenova OV, van de Rijn M et al (2010) Human melanoma-initiating cells express neural crest nerve growth factor receptor CD271. Nature 466:133-177

52. Meyer MJ, Fleming JM, Ali MA, Pesesky MW, Ginsburg E, Vonderhaar BK (2009) Dynamic regulation of CD24 and the invasive, CD44posCD24neg phenotype in breast cancer cell lines. Breast Cancer Res 11:R82

53. Roesch A, Fukunaga-Kalabis M, Schmidt EC et al (2010) A temporarily distinct subpopulation of slow-cycling melanoma cells is required for continuous tumor growth. Cell 141:583-594

54. Chang $\mathrm{HH}$, Hemberg $\mathrm{M}$, Barahona $\mathrm{M}$, Ingber DE, Huang $\mathrm{S}$ (2008) Transcriptome-wide noise controls lineage choice in mammalian progenitor cells. Nature 453:544-547

55. Lewis MT (2010) The more things change... the more things change: developmental plasticity of tumor-initiating mammary epithelial cells. Breast Cancer Res 12:101

56. Musgrove EA, Sutherland RL (2009) Biological determinants of endocrine resistance in breast cancer. Nat Rev Cancer 9:631-643

57. Dontu G, El-Ashry D, Wicha MS (2004) Breast cancer, stem/ progenitor cells and the estrogen receptor. Trends Endocrinol Metab 15:193-197

58. van der Burg B, de Groot RP, Isbrucker L, Kruijer W, de Laat SW (1991) Oestrogen directly stimulates growth factor signal transduction pathways in human breast cancer cells. J Steroid Biochem Mol Biol 40:215-221

59. van der Burg B, Rutteman GR, Blankenstein MA, de Laat SW, van Zoelen EJ (1988) Mitogenic stimulation of human breast cancer cells in a growth factor-defined medium: synergistic action of insulin and estrogen. J Cell Physiol 134:101-108 